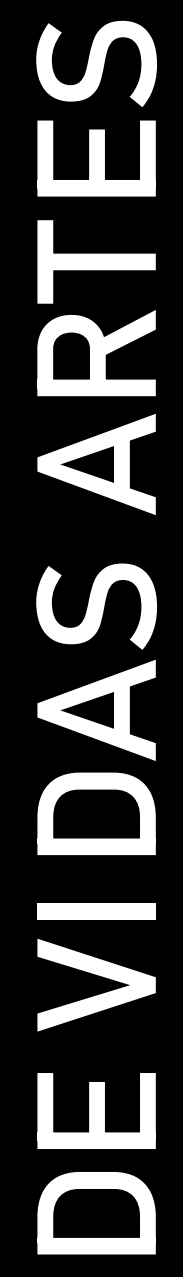

PAULA GUERRA E LÍGIA DABUL (EDS.) 


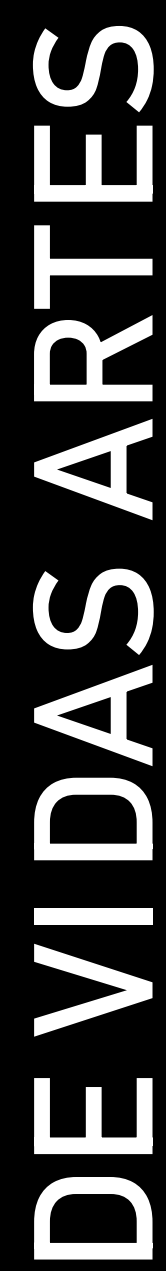

\section{PAULA GUERRA E LÍGIA DABUL (EDS.)}

Design por Irandina Afonso

Ilustração da Capa por Lua Celina

Publicado em Setembro 2019

Universidade do Porto. Faculdade de Letras

[University of Porto. Faculty of Arts and Humanities]

Porto, Portugal

ISBN 978-989-8969-18-7

Suporte: Eletrónico - Formato: PDF / PDF/A 


\title{
IV.2. Cultura pop e nostalgia na contemporaneidade: apontamentos iniciais sobre arquivo, memória e o YouTube como um espaço heterotópico
}

\author{
IV.2. Pop culture and contemporary nostalgia: initial \\ notes on archive, memory and YouTube as a heterotopic \\ space
}

\section{Thiago Pereira Alberto}

\begin{abstract}
Resumo
No presente capítulo pretendemos analisar o YouTube, através da possibilidade do arquivamento infindável que o Website parece proporcionar, como um campo de análise notável em desvelar a relação entre arquivo e memória como um traço formativo para a noção de cultura pop na contemporaneidade. Reconhecendo o lugar ocupado pelo pop na expressão subjetiva do sujeito inserido na cultura atual, buscamos analisar o site como um espaço heterotópico e deste modo, um imenso repositório da experiência individual, traduzida no armazenamento digital da reminiscência pessoal, ativando nos usuários escavações afetivas, onde criam-se produções de sentido específicas centrados nas especificidades deste aparato que, em seus aspectos relacionais, parecem formatar um importante fenômeno comunicacional centrado na ideia de nostalgia e consumo retro.
\end{abstract}

Palavras-chave: arquivo, cultura pop, nostalgia, YouTube.

\begin{abstract}
In this chapter we intend to analyze YouTube, through the possibility of the endless archiving that the site seems to provide, as a remarkable field of analysis in unveiling the relation between archive and memory as a formative trait for the notion of pop culture in the contemporaneity. Recognizing the place occupied by pop in the subjective expression of the subject inserted in the current culture, we seek to analyze the site as a heterotopic space and thus an immense repository of the individual experience, translated into the digital storage of personal reminiscence, activating in the users affective excavations, where specific productions of meaning centered on the specificities of this apparatus are created which, in their relational aspects, seem to form an important communicational phenomenon centered on the idea of nostalgia and retro consumption.
\end{abstract}

Key words: archive, pop culture, nostalgia, YouTube.

\section{Introdução}

Partindo da premissa de que vivemos tempos de transformações espessas nos processos comunicacionais e, por conseguinte, dos nossos modos de vida, sublinhamos no presente capítulo algumas questões primordiais relativas aos lugares do arquivo e da memória a partir das alterações tecnológicas advindas destas novas possibilidades - onde os média 
reconfiguram práticas, rotinas e possibilitam redimensionamentos de diversas ordens (do coletivo ao individual) no tecido social. Filtramos nossa análise a partir de balizas que são caras à nossa pesquisa de doutoramento ${ }^{193} \mathrm{e}$, dessa maneira, o exame proposto aqui se dá em três etapas. Inicialmente, tentamos dimensionar sinteticamente a noção de uma cultura pop assumindo-a como um campo que modula diversas sensibilidades do sujeito contemporâneo. Entre estes sensíveis, destacamos uma expressão que consideramos central, a nostalgia, e sugerimos como ela se conforma diante das relações entre arquivo e memória em relação ao repertório desta mesma cultura pop.

Tomamos a nostalgia como um pathos, onde se estabelece como uma "estrutura de sentimento" que cumpre objetivos societários como reconhecimentos e representações de pessoas e tipo de pessoas, sensibilidades, em lugares e tipos de lugares e identidades, que podem ser praticados numa gama muito extensa, "das formas mais coletivas às mais individuais", como sugere Williams (1992: 128). Nessa direção, esta pathemia 'contamina' tanto aspectos objetivos da cultura pop - em vídeos, música, cinema, televisão, através de noções como retromania, sugerida por Reynolds (2011) - quanto na forma em que os sujeitos expressam e partilham esse sentimento. Assim, nosso segundo vetor analítico se dá em pensar como expressam e se articulam os média numa era de redes, dispositivos e interações online em um contexto de complexas transformações do status da memória e da percepção temporal na cultura contemporânea, a partir da plataforma YouTube como objeto de exame. Tanto no ato de postar e compartilhar materiais audiovisuais quanto no registro de comentários, o YouTube parece se apresentar como um novo território de fronteiras fluídas, muito além do seu apelo como inovação tecnológica: se situa como um dos lugares da experiência de uma ação que já não se confunde com o aqui (espaço) e agora (tempo) da ação imediata. Dessa forma, para além de atestar o lugar ocupado do pop na expressão subjetiva do sujeito inserido na cultura atual, o YouTube registra também a centralidade dos discursos sobre a memória destas mediações ao se dispor como um repositório midiático ideal - um arquivo - para visualizações nostálgicas dos usuários, que confirmam a força de um pathos nostálgico ao registrar, através de postagens, comentários

\footnotetext{
193 O capítulo aqui apresentado é um recorte da tese "But Don't Forget The Songs That Saved Your Life: The Smiths, YouTube e a centralidade da nostalgia no pop contemporâneo", orientada pela Professora Doutora Simone Pereira de Sá na Universidade Federal Fluminense (Niterói/RJ) e com Estágio Doutoral na Universidade do Porto sob supervisão da Professora Doutora Paula Guerra.
} 
e compartilhamentos, performatizações de afetos, gostos, lembranças e narrativas memoriais (Guerra, 2018).

O nosso último ponto consiste em sugerir primeiros apontamentos para se pensar esta plataforma como um espaço heterotópico ${ }^{194}$ e, deste modo, um imenso repositório da experiência individual, traduzida no armazenamento digital da reminiscência pessoal. O conceito de heterotopia, proposto por Foucault (2001), sugere, através de leituras amplas, a existência de outros espaços que são mapeados como uma espécie de justaposição de diferentes tempos e diferentes lugares que se conectam sob a lógica de rede, termo este caro ao pensamento contemporâneo nos estudos de comunicação. Dessa forma, sugerimos o YouTube como um possível campo de análise notável em desvelar um lugar para a memória da cultura pop contemporânea.

A partir de um amplo escopo de autores (Boym, 2001; Davis, 1979; Holbawchs, 2006) podemos pensar que a nostalgia é uma espécie de memória amplamente subjetivada, valorizada e produzida pela reflexão sobre as coisas (objetos, pessoas, experiências, idéias) associadas ao passado, atravessada e posteriormente externada por emoções, reflexões, idealizações. Seria uma forma de tonalizar as lembranças de forma ainda mais explícita, positivamente ou negativamente. Para além disso, é um sentimento do nosso self: como sugere Hall (2005), se a noção de identidade também se constrói a partir dos nomes que damos às diferentes maneiras que nós estamos posicionados, e nos posicionamos, nas/e às narrativas do passado, a nostalgia seria um dos meios à nossa disposição para o interminável trabalho de construção, manutenção e reconstrução de quem somos (Davis, 1979). Portanto, se estamos inseridos em um contexto de sociedade, a nostalgia não é apenas acionada pelo passado pessoalmente experimentado, mas também pode ser evocada por entendimentos coletivos do passado, que não necessariamente precisam ter sido vividas por alguém. A sentimentalização da memória surge tanto de um passado pessoalmente

\footnotetext{
194 Proposta por Foucault em 1966, em uma conferência radiofônica na França, mas só publicada em "Outros Espaços" (1984), a noção de heterotopia diz de lugares pertencentes à dimensão teológica do futuro (ou seja, utópicos, no sentido de terem uma dimensão do impossível), mas que se concretizam como espaços existentes, espaços de exceção, espaços materiais e imateriais que vigoram como convergentes contestações míticas e reais do espaço que vivemos. São as nossas chances de ver "outros espaços" escondidos nos signos e situações por vezes óbvias do real; ou, como aponta Soja (1995: 15), outros espaços que estão frequentemente "obscurecidos da visão pela ênfase excessiva na sua opacidade empírica, ou em sua transparência idealizada"
} 
experimentado (autobiográfico) quanto de uma interpretação compartilhada de um passado (coletivo), em processos que não são necessariamente mutuamente exclusivos, pois uma rede de associações pode ter elementos de cada um.

Tomando como exemplo a música (uma das expressões mais notáveis da presença da cultura pop), nas últimas décadas, um amplo escopo de autores (De Nora, 2001, Van Djick, 2015) propõem pensar seu papel tanto como componente vital da expressividade e lembrança individual das pessoas, tanto como um elemento constitutivo da construção de identidade coletiva e patrimônio cultural, de onde memória e constituição do self se entrelaçam de forma marcante. Logo, podemos assumir, que como outras possibilidades de representação dos sujeitos, a música $p o p^{195}$ se apresenta como uma ferramenta fundamental para entender "nós mesmos a partir de formas históricas, étnicas, classes sociais, gêneros e temas nacionais" e afirma-se como "uma experiência de identidade", ao oferecer um senso de você mesmo e dos outros ao compartilhar sentimentos, valores, e gostos (Frith,1996: 85).

Compartilhar, ouvir, trocar músicas e falar sobre ela, além de ser uma forma de ritualizar seu uso, pode criar uma sensação notável de pertencimento, ao conectar o senso de identidade de uma pessoa a uma comunidade e a uma geração, ou seja, a um espaço e tempo específicos. Diante disso, apontamos o papel da lembrança neste processo diante da possibilidade de expressão da memória em um contexto onde podemos plenamente nos reconectar (através de um complexo espesso de sistemas midiáticos, redes sócio técnicas e demais dispositivos interacionais) 'voltar' para os antigos tempos/espaços que cumpriram papéis importantes ao dimensionar nossas existências.

Assim, nos interessa pensar a presença de elementos da cultura pop, como a música, como um estímulo das memórias do passado, através de situações geradas no presente. Em suma, a nostalgia, neste encadeamento lógico, nasce de um agora (a escuta de uma canção, a audiência de um vídeo

\footnotetext{
195 Assumimos aqui, de início, que as pessoas se tornam conscientes de suas memórias emocionais e afetivas, pessoais ou coletivas, por meio da cultura pop. Tomando como exemplo a música, Cross (2015) nos lembra que a canção popular criou um léxico único de memória musical: a melodia pop moderna possúi enquadramentos estruturais que também estão pautados pela sua capacidade de fácil memorização, onde ela deve propôr ao ouvinte algo curto e familiar, fácil de cantar e tocar, que soe atual e que, frequentemente tematize questões universais, o que explica por exemplo a profusão de músicas sentimentais ou românticas.
} 
antigo), desejando um antes (onde eu estava quando estes elementos sonorizavam minha vida; com quem eu estava; o que aconteceu), considerando que a rememoração sentimentalizada é, seguramente, mais um efeito na longa lista de sentidos possibilitada pela presença cotidiana da música em nossa sociedade (De Nora, 2001). Assim, se a nostalgia ascende como um elemento marcante na identidade da vida contemporânea, é porque também atravessa a cultura pop, como mediação e modulação do self de amantes de música, ou parte da constituição destes como "sujeitos pop" (Alberto, 2013), especialmente com as possibilidades de arquivamento midiático atuais. Este cenário proporciona um campo extenso de novas investigações, no inseparável âmbito das mensagens e dos meios no tecido comunicacional.

\section{O passado como aspecto central da cultura pop contemporânea}

Inicialmente, torna-se importante balizar aqui o que chamamos de cultura pop, no sentido de entender qual o lugar do arquivo neste contexto e em como ele impulsiona uma prática memorialista em plena atuação na contemporaneidade, já que tensionamos a ideia de cultura pop para além da concepção por vezes estratificada de algo efêmero (de extinção em curto prazo) e descartável (facilmente esquecível) - mas sem deixar de considerar tais efeitos como distinções importantes em nosso escopo de análise. Para além, pensamos a ideia de pop aqui como uma linguagem, historicamente derivada da pop art, na década de 1950, mas que foi ampliada para diversas outras práticas sociais desde então, se configurando em uma espécie de sensibilidade, que atravessa o sujeito contemporâneo através de seus variados espraiamentos midiáticos (músicas, filmes, séries, moda, cultura digital) e que, por vezes, se caracteriza por sua possibilidade de permanência na experiência afetiva de cada um; experiência que, do ponto de vista do acesso, se configura de formas cada vez menos perenes, em função das possibilidades de arquivamento gerados pelo progresso tecnológico, simbolizado no presente artigo pelo site YouTube.

Falamos, portanto, de uma vida mediada pelo pop, que através de representações e reconhecimentos da cultura midiática que nos cerca, vai responder a uma nova sensibilidade, percebida no sentido de decodificar uma noção de pop em uma espécie de autoconsciência, já que pensar a cultura pop como uma "espécie de continuação da vida por outros meios" (Alberto, 2013: 78) é também entender que o pop é fruto da codificação entre desejos 
pessoais e regimes estéticos vindos da mutação que a arte e a produção cultural sofrem a partir dos efeitos dessa sociedade informatizada e midiatizada que vivemos. Ou seja, o pop impulsiona processos de subjetivações nos sujeitos, pois também é também "uma presença cotidiana e constante em nossa vida ${ }^{196}$ a diária, enquanto ligamos e desligamos, indo de um espaço, de uma conexão midiática para outra" (Silverstone, 1999: 20).

Desse modo, é via cultura pop que o sujeito contemporâneo recolhe algumas de suas referências imediatas, onde tece sua cartografia pessoal para ler a sociedade onde está inserido; seu innerswelt (o self interior) é também moldado pelo lebbenswelt (o mundo da vida, exterior), o que vê na televisão, pelo que escuta no rádio, pelos filmes a que assiste, pelos sites que frequenta. E assim, temos o cenário de uma vida mediada pelo pop, onde a imagerie e a sensibilidade pop, notada no campo das artes visuais na segunda metade do século $X X$, se cristaliza no corpo contemporâneo transcrevendo subjetividades. Assim, em uma tentativa de sistematizar e sumarizar uma dimensão histórica, convocamos Silveira (2013: 9-10), para traçar alguns eixos que são definidores para a concepção de uma noção espessa do que é cultura pop, onde já destacamos sua aderência aos meios de comunicação de massa, ao vê-la como um braço permanente da cultura midiática, já que ambos possuem não apenas historiografias atreladas, mas como o balaio pop, em suma, diz de um "grupo de objetos culturais voltados à disseminação midiática mais acentuada possível". Para além, o autor sublinha, como traços formativos do pop: a) a ideia de uma cultura de mercado, sob a lógica de um regime mercantilista, capitalista, produzido sob o "imperativo do lucro"; b) o caráter hedonista e de entretenimento, capaz de despertar comportamentos apaixonados, de fixação, o "domínio dos afetos e certa antropologia das obsessões", como nota o autor; c) a cultura jovem urbana, eivada na discussão cara ao século passado entre a dissolução ou os câmbios entre alta e baixa cultura, que tem origem, tanto nos Estados Unidos nos baby boomers do pós-guerra, quanto nas ordens periféricas europeias, que se diferencia (e se afirma e se identifica) na distância com o

\footnotetext{
${ }^{196}$ Também por isso, o pop nos parece inescapável, até por sua filiação arterial com a mídia, que opera hoje como uma espécie de "organizador principal da sociedade", seu processo interacional de referência, como aponta Braga (2006:2). Mais do que modos de organizar e transmitir mensagens, a midiatização se transforma em um padrão para ver as coisas e articular pessoas; é parte fundamental na construção do tecido social. A cultura pop parece atuar de forma semelhante, transfigurando os desejos, âmbitos de criação e interação dos sujeitos midiatizados, sem necessariamente corresponder a algo alienante ou meramente devoto às lógicas mercantilistas, e que também modula subjetividades de forma mais individual.
} 
beletrismo, e a empáfia da elite cultural, ou seja, é decorrente dos ajustes de conta, das reapropriações simbólicas, das guerrilhas semióticas da working class; d) por último, seu caráter transnacional, que instaura comunidades, gostos e repertórios que rescindem de barreiras geográficas ou de soberanias políticas.

Pretendemos acrescentar a esta eficiente sistematização o caráter "retrovisor" do pop contemporâneo, ou seja, a capacidade da cultura pop hoje se alimentar de seu próprio repertório; a lógica pop will eat itself espelhada em sua necessidade de canonizar suas consagrações em repetições que se performam continuamente através de remediações e intermediações nos dispositivos midiáticos disponíveis na contemporaneidade. Aqui, destacamos a centralidade do arquivo, via mídia, como força propulsora do pop contemporâneo; o que pode dizer de um sensível nostálgico, cimentado sob uma possível febre memorialista, como notada por autores como Reynolds (2011) e Huyssen (1996).

Essa característica, marcada por um tom intoxicante e febril, Reynolds (2011) chama de retromania: o grande apego da cultura pop ao seu próprio passado e o constante uso de referências a si mesmo, bem como a volta de diversos elementos de décadas passadas ao presente. Assim, podemos pensar no retro neste ambiente como um arranjo que envolve as possibilidades de replicar com o máximo de exatidão traços marcantes de um passado relativamente imediato, a partir da farta disponibilidade de documentação arquivada (fotografias, vídeos, gravações de música, Internet) que se conecta diretamente com a cultura de consumo e pop-portanto o retro não está nos museus ou nos leilões da alta cultura e sim nos sebos, mercados de pulga, etc. O retro não necessariamente idealiza ou sentimentaliza em excesso o passado: sua tessitura nostálgica se liga à ideia de diversão e um possível charme e diferencial estético, sendo assim pouco purista e mais irônico e eclético, usa este passado como um arquivo de materiais onde seja possível extrair um capital cultural, ou subcultural (que, especialmente nas últimas décadas, é ilustrado pela figura do hipster) a partir de reciclagens e recombinações. Neste sentido, talvez o retro é mais a respeito de uma espécie de estetização do presente do que o desejo de voltar ao passado que 
intenta rever e reviver, mas sem neutralizar esse inegável verniz nostálgico ${ }^{197}$. Como sugere Cross (2015), o retro se cristaliza como uma past fashion (uma moda passadista), uma modalidade de consumo nostálgico que exprime a identificação com o passado com e através de suas distintas materialidades (arte, música, roupas) que produz formas distintas de memory making (ou produção de memória) e corporifica passados particulares ou coletivos em possessões pessoais, exprimindo uma fixação pela experiência nos chamados anos de formação e concatena a memória tanto como um sinal de distinção, de autoridade, de respeito e evocação às origens (significado no colecionismo, no detalhismo, no fetiche por relíquias), como recordações íntimas.

Esse panorama, no ambiente da música pop, é constituído através de diversos elementos: desde a quantidade relevante de documentários em torno de certa historiografia pop, passando pela lógica fantasmagórica do sampler e dos mash-ups; alcança a reabilitação do vinil como mídia colecionável e também se espelha nas reuniões (ou revivals) de bandas, canções e até mesmo eventos que o tempo deixará para trás. Em suma, Reynolds (2011), a partir de Huyssen, sugere a ideia que vivemos um tempo de recordação total (total recall), impulsionado por um pathos nostálgico, onde o pop e a memória são amplamente conectados através de novos dispositivos, como o YouTube, satisfazendo uma espécie de afeto saudosista particular para o usuário contemporâneo.

Este último aspecto é fundamental para uma caracterização personalista da paisagem atual, já que a retromania, como sublinha Reynolds (2011), não é um fenômeno novo: historicamente a cultura passa sazonalmente por distorções e revivals criativos. Mas o aspecto de recordação instantânea, possibilitado pela revolução da informação (simbolizado fortemente pela Internet) diferencia o fenômeno hoje, e nos inspira a apensar na centralidade que o arquivo (como um portal para o passado, que conforta e ao mesmo tempo está em constante atualização) possui na paisagem pop contemporânea, no sentido de estarmos expostos constantemente aos símbolos que acionam memórias. Dessa maneira, ressaltamos a nostalgia como um sentimento impulsionador destas idas e

\footnotetext{
${ }^{197}$ Diferentemente de vintage, que se refere a objetos materiais de uma época, os "originais", em oposição à novidades nostálgicas, que se orientam na reprodução de coisas antigas. Assim, retro e vintage são modalidades relacionáveis, mas não idênticas.
} 
vindas a signos que remontam nossas lembranças e o papel importante que ela parece ocupar no contexto da fruição de cultura pop na contemporaneidade. Como Van Dijck (2015) elabora, afetos e emoções estão ligadas a este material em particular, porque o processo de recordação é um agente ativo e interpretativo relacionado a uma consciência situada no mundo: os elementos do pop que nos atravessam, como tantas outras coisas, são sinais de uma época, uma baliza temporal que incorpora (ou vem incorporada) na lembrança de quadros sociais mais amplos.

Nessa direção, nos parece pertinente acionar Boym (2001) e suas percepções a respeito do tema, operacionalizadas no que a autora vai chamar de restorative nostagia relativas à uma ordem mais coletiva, e a reflective nostalgia, relacionada às individualidades. Enquanto a nostalgia restauradora evoca o passado e o futuro nacional; a nostalgia reflexiva está mais conectada a memória individual e cultural. A nostalgia restauradora quer reconstruir emblemas e rituais de casa e da terra natal; a reflexiva é mais orientada para uma narrativa individual que saboreia detalhes e os sinais memoriais, preza fragmentos de espaço e tempo, como nota Boym (2001):

\begin{abstract}
Ela constitui estruturas sociais compartilhadas de recordações individuais. São dobras de memória do fã, e não prescrições para uma recordação modelo (...) $O$ compartilhamento de estruturas cotidianas da memória coletiva ou cultural nos oferecem meras indicações para reminiscências individuais que possam sugerir múltiplas narrativas. Estas narrativas têm uma certa sintaxe (bem como uma entonação comum), mas nenhuma parcela única (Boym, 2001: 61).
\end{abstract}

A nostalgia reflexiva, como afirma Boym (2001: 49), não é patológica, mas mítica: em busca do "mito cultural, entendido como uma narrativa recorrente, percebida como natural e do senso comum em uma determinada cultura"; pressupostos que ajudam a naturalizar a história e torná-la habitável. Se a saudade original era uma doença de soldados suíços que não desejavam lutar e morrer longe de sua terra natal, a nostalgia pop, como a autora sugere, é frequentemente uma doença de "lustres da guerra", ou seja, das simbologias míticas construídas no ambiente da cultura pop, como músicas, shows, propagandas, programas televisivos e videoclipes.

\title{
3. YouTube como arquivo possível para a cultura pop
}

Portanto, se a partir do início do século XX, a nostalgia ${ }^{198}$ perde em definitivo seu caráter patológico (uma visada que vinha perdendo força histórica muito

\footnotetext{
${ }^{198}$ Nostalgia tem seu significado primário etimológico e social como ligado à ideia de "saudades de casa", do original homesick. Um ardor debilitante em retornar a sua terra nativa: ou seja, originalmente é uma dor ligada à idéia de espaço (ou melhor, do desconforto com algum espaço), mais que de tempo. Seu surgimento foi "diagnosticado" pelo psiquiatra Johannes Hofer e se refere aos soldados suíços do século
} 
anteriormente, sublinhamos) e se torna uma emoção universal, em um mundo que tem seu ritmo cotidiano agora alterado pelo desenvolvimento de novas tecnologias, os elementos típicos do pop (música, cinema, publicidade, séries televisivas e quetais), naturalmente, serão objeto de diferentes dimensões atravessadas por este pathos nostálgico a que aludimos aqui. Dentro do balaio das plataformas mediáticas que alteraram a paisagem comunicacional da contemporaneidade, o YouTube se apresenta como um dispositivo adequado: espécie de arquivo frequentemente tomado como infindável e seguro ${ }^{199}$, um guardião possível da mítica pop que atravessou e se solidificou na cultura hodierna, onde o proverbial retorno ao lar é garantido a cada visita aos vídeos disponíveis na plataforma, de antigas propagandas a desenhos animados que marcaram época, passando por clipes, vídeos ao vivo, etc. Assim, a noção de retromania nos oferece aporte para pensar que a nostalgia, quando ancorada em um porto de infindáveis possibilidades de arquivo como o YouTube, se mostra uma marca importante no contexto da cultura pop.

Um aspecto destacável de todo este processo é o fato de, a partir das possibilidades oferecidas pelos aparatos mediáticos atuais, objetivado aqui no site YouTube, criam-se produções de sentido específicas centrados nas especificidades desses aparatos o que, em seus aspectos relacionais, parecem formatar um importante fenômeno comunicacional centrado na ideia de nostalgia e consumo retro. Como marca de sua conexão arterial com a cultura midiática, como afirmamos anteriormente, a cultura pop está ligada às expressões comunicacionais, musicais, audiovisuais, comportamentais, entre outras, surgidas no século $\mathrm{XX}$, que se valeram fortemente da evolução dos dispositivos midiáticos, tanto em suas técnicas de produção, armazenamento e circulação como em suas condições de produção e reconhecimento.

Em contextos sócio-técnicos, e fazendo um recorte específico no campo da música, a título de ilustração, pode-se também relacionar a configuração da cultura pop ao desenvolvimento dos aparelhos de reprodução e gravação audiovisual, o que envolve as lógicas mercadológicas da indústria fonográfica, os suportes de circulação das canções e os

\footnotetext{
XVII e seus males de batalha, ou seja, seu medicamento seria pegar o primeiro navio de volta para casa, para o mundo familiar.

${ }^{199}$ Essa percepção de que os dispositivos de arquivamento e partilha de dados entre usuários teriam em plataformas como o YouTube, Instagram e demais redes sociais uma "segurança" da permanência de seus conteúdos seguramente merece uma análise mais complexa (que por questões de espaço, não realizamos aqui), especialmente diante de acontecimentos recentes como a desativação de sites como o MySpace, realizada em 2019, que gerou a perda de incontáveis arquivos musicais que lá estavam depositados.
} 
diferentes modos de execução e audição relacionados a essa estrutura. Falamos aqui do entendimento da mediação dos objetos técnicos na construção da experiência pop. A partir destas mudanças, notamos que o cenário da indústria cultural e das interações midiatizadas oportuniza relações sociais e subjetivas que podem conectar diferentes tempos e espaços no tecido social da contemporaneidade. Afinal, no início deste século XXI, a produção e o consumo da música passaram por um processo de descentralização marcante: deslocamentos que modificaram completamente a formar de se fazer, ouvir e consumir música. Entre os fatores essenciais para tais mudanças, destacamos a solidificação da Internet e de novos recursos tecnológicos - como o YouTube, por exemplo - como plataforma central para a música, onde o papel antes representado pelos discos de vinil, fitas cassetes, compact discs e até mesmo sua reprodução televisiva em canais específicos como a Music Television (MTV) tem sido gradualmente substituído por novos formatos. Como nota Pereira de Sá (2014: 538),

\begin{abstract}
Nos últimos vinte anos, ocorreu um deslocamento em prol de maior atenção às materialidades dos meios tanto quanto ao papel central das mediações tecnológicas para a experiência musical. O advento da comunicação digital e da Internet contribuiu para desnaturalizar a relação entre tecnologias e cultura de maneira geral e da música, de maneira específica; recolocando, assim, questões cruciais sobre o papel das tecnologias num ambiente reconfigurado pelo Napster, pela música circulando através de múltiplos suportes, pelos blogs e plataformas musicais, pelo formato MP3 e pelas mídias móveis e locativas, que alteraram a paisagem sonora contemporânea. (Pereira de Sá, 2014: 538).
\end{abstract}

Destacamos aqui o YouTube como um destes alteradores fundamentais da paisagem contemporânea, através de um breve histórico que nos guia no sentido de entender as especificidades deste aparato midiático. Fundado por Chad Hurley, Steve Chen e Jawed Karim, ex-funcionários do site de comércio on-line PayPal, o site foi lançado oficialmente sem muito alarde em junho de 2005; afinal, quando surgiu, o YouTube era "apenas" mais uma novidade no fértil terreno de novas possibilidades de mediação midiática da Internet. Como nos lembram Burguess e Green (2009), a inovação original era de ordem tecnológica, mas não exclusiva, e o site era um entre os vários serviços disponíveis que buscavam disponibilizar novas técnicas para maior compartilhamento de vídeos na Internet.

Mas, captando as mudanças constantes na sociedade da informação (como interatividade, capacidade de arquivamento e simplificação de sistemas) e as incorporando no site, podemos afirmar, hoje, que o site reflete uma trajetória vitoriosa, que já deixa marcas indeléveis tanto no tecido social contemporâneo, quanto na história da Internet: segundo dados divulgados 
pela plataforma ${ }^{200}$, o YouTube tem mais de um bilhão de usuários - quase um terço de todas as pessoas na Internet - e todos os dias as pessoas assistem centenas de milhões de horas no YouTube (e, como acertadamente firmam neste estatuto de dados, geram "bilhões de pontos de vista"); lançou versões locais em mais de 70 países e é navegável em um total de 76 idiomas diferentes (cobrindo 95\% da população da Internet). Seus dados ainda destacam a grande audiência entre jovens (18-34 anos) que, tanto nas versões online quanto na versão móbile já superam o alcance de qualquer rede de TV a cabo nos Estados Unidos, mas lembram de que $80 \%$ dos usuários do YouTube estão fora dos EUA. Segundo Burguess e Green (2009), Jawed Karim - o terceiro cofundador que deixou o negócio para voltar à faculdade em novembro de 2005 - aponta quatro recursos essenciais oferecidos pelo site, para justificar o seu sucesso: a) recomendações de vídeos por meio da lista de "Vídeos Relacionados"; b) um link de e-mail que permite o compartilhamento de vídeos; c) comentários (e outras funcionalidades inerentes a redes sociais); d) um reprodutor de vídeo que pode ser incorporado em outras páginas da Internet.

O surgimento destas funções, apontadas como as chaves fundamentais para a inserção do YouTube no cotidiano de seus usuários, foram implementadas após uma iniciativa comicamente fracassada de popularizar o site, que incluíram a oferta de 100 dólares para "garotas atraentes" que postassem mais de dez vídeos. De acordo com Karim, os fundadores não receberam sequer uma resposta a essa oferta. Mas o tempo dos fracassos durou pouco após a aplicação das funções citadas: depois do seu primeiro aniversário de existência, o Google, até hoje o site mais acessado em todos os tempos, pagou em outubro de 2006, 1,65 bilhão de dólares para ter o site sob sua chancela, informação que diz não apenas do fato de que as redes sociais, para além de serem uma excelente oportunidade de negócios, ou uma plataforma de distribuição de mídia, (ou como sinaliza o impessoal primeiro slogan do YouTube: "Your digital video repository"), mas que na verdade sinaliza um processo (ou uma série de novas configurações) que dizem respeito ao próprio estar no mundo hoje, como no atualizado e mais personalista bordão "Broadcast yourself" (ou transmita-se, em tradução literal).

200 Dados disponíveis em https://www.youtube.com/yt/press/statistics.html 
Se emitir é existir, para falar como Türcke (2010), que sugere este enquadramento como apontamento filosófico da condição contemporânea, acreditamos que o YouTube, através especificamente de algumas suas funções que destacamos aqui (os uploads de vídeos e os posteriores compartilhamentos e os comentários) pode ser assim visto sob uma luz mais complexa como um imenso repositório da experiência subjetiva, traduzida no armazenamento digital da memória corpórea. Assim, em um período de transformações espessas do processo comunicacional, a própria noção de tempo e de espaço, e suas rupturas acionadas por transformações tecnológicas, se apresentam como diapasões possíveis para entender o ambiente midiático contemporâneo. Portanto, a plataforma atua também como um importante mecanismo de mediação para a esfera cultural pública, sendo um espaço de circulação de vídeos de representantes da mídia tradicional, organizações diversas e pessoas comuns, e assim se constitui como um instrumento de "viabilização de encontros de diferenças culturais e o desenvolvimento de 'audição' política entre sistemas de crenças e identidades" (Burguess e Green, 2009: 107).

A partir disso, talvez possamos acrescentar mais uma questão que parece fundamental para não apenas justificar o sucesso do YouTube, mas também sua centralidade na sociedade contemporânea: como ele consegue tensionar dois eixos sob os quais o próprio desenvolvimento de uma civilização orbita, a relação entre tempo e o espaço. E quando a nossa relação com o tempo e o espaço é profundamente transformada na era digital, com as noções de distância e delay erodidas, cabe também detectarmos uma das marcas essenciais do site: a possibilidade de ser visto como um expressivo arquivo, lugar de representação de todos os tempos e espaços, espaço adequado para a expressão de alguma forma de subjetividade pop (Alberto, 2013) e memorial tão acionada pelo ambiente da cultura pop. Sob essa baliza, - YouTube parece oferecer para o usuário a possibilidade de acesso às informações de forma randômica ou organizada, onde o próximo e o longe, o lado a lado e o disperso, estão justapostos em frente aos nossos olhos; parentes de bibliotecas ou museus, onde somos capazes de reorganizar cronologias e espaços, resultando em um grande saber imediato, através da compilação infinita de dados. Propostas tanto como as de canais específicos voltados para épocas determinadas (são extensos os exemplos de compilações ao estilo flashback espalhadas pelo site) como a de postagens 
aleatórias e sem chancelas específicas de milhares de usuários, o site perfila uma compilação gigantesca e de registros audiovisuais pop do passado, que encontram no YouTube um pouso que parece coerente, pela própria lógica do site de dispensar modelos de arquivamentos estáveis e, ao que o contexto indica até o momento, findáveis.

\section{Apontamentos para o YouTube como um espaço heterotópico}

Dessa maneira, a ideia de acumular o máximo de dados possíveis como algo que remete à vontade de constituir uma espécie de arquivo geral nos leva ao conceito de heterotopia, de Michel Foucault, que se apresenta como uma definição operatória para o YouTube sob uma perspectiva de expressão nostálgica da (e na) cultura pop. Suspeitando que a nova mania do século $\mathrm{XX}$ seria o espaço - em oposição ao tempo, chave de entendimento da civilização dos tempos anteriores - Foucault (2001) sugere outros parâmetros de leitura, dizendo de uma era do espaço, do simultâneo, da justaposição; o mundo menos como uma "grande via que se desenvolveria através dos tempos e mais como uma rede que religa pontos e entrecruza sua trama" (Foucault, 2001: 412). Se o próprio espaço possui uma história (que o autor classifica através de períodos anteriores como o espaço de localização, na Idade Média, ou o espaço de extensão, a partir do século XVII), ele sugere que o século XX seria a era do espaço de posicionamento, definido pelas relações de vizinhança entre pontos ou elementos, descritos como séries, organogramas, grades e redes; um espaço heterogêneo, vivido no interior de um conjunto de relações. Para o autor, esses posicionamentos se alocam em dois grandes tipos: a utopia e a heterotopia. Enquanto entende o primeiro como um lugar essencialmente irreal, da realização de uma sociedade aperfeiçoada, as heterotopias são os espaços que efetivam, mesmo que temporariamente, as utopias. Espaços localizáveis, nos quais "os posicionamentos reais que podem se encontrar no interior de uma cultura estão ao mesmo tempo representados, contestados, invertidos - lugares que estão fora de todos os lugares" (Foucault, 2001: 415).

Espécie de encontro entre o mítico e o real do espaço em que vivemos, onde somos capazes de estar em ruptura absoluta com o tempo tradicional; portanto também heterocronias, quando os homens se encontram em uma espécie de "ruptura absoluta com seu tempo tradicional" (Foucault 2001: 418), seja a suspensão crônica específica possibilitada por cidades de veraneio, como ele sugere, ou pelo tempo que se acumula infinitamente, como em 
museus e bibliotecas. Como Soja (1995:15) reforça, heterotopias tratam-se de lugares de convergência, que se tornam enredados, onde se realiza a complexa justaposição e simultaneidade das diferenças, "no mesmo espaço que fertiliza a heterotopia com significados sociais, culturais e conectividade. Sem essa carga, o espaço permaneceria fixo, morto, imóvel, não dialético". Foucault propõe, assim, pensar o espaço não mais como a esfera da fixação e da estabilidade (em um contraponto histórico com o tempo, que era o diapasão da mobilidade e da vida). Assim, é a ideia do espaço fluido, não estático, que determina a fantasia de uma vida interminável, ou determinada pelos limites do espaço-tempo: fala-se enfim de um lugar de todos os tempos que esteja ele próprio inacessível a sua agressão, espécie de cumulação perpétua e infinita do tempo em um lugar que não mudaria.

Essa ideia de tudo acumular remete à vontade de constituir uma espécie de arquivo geral, que possibilitaria um grande saber de acesso imediato. Nessa direção, podemos pensar o YouTube como uma forma de realização desse espaço/arquivo que, através de sua (em teoria) infindável capacidade de armazenamento, que pode vir a afirmar ao sujeito a possibilidade de um repositório infinito - pelo menos enquanto dure. Um espaço ideal, portanto, para a expressão da nostalgia, atuante não apenas como função de uma instância viva, espontânea, presente a si mesma, mas também como o lugar de uma inscrição que faria transbordar os limites entre os espaços e tempos: nostalgia como princípio de contemporaneidade, um sensível saudosista explicitado (e realizado) neste dispositivo midiático.

Desta maneira, na proposta de examinar o pop como um modulador de sensíveis que, por meio da lógica do arquivo, permite investigar o desejo de consumir elementos do passado proporcionado pelas possibilidades que o ambiente digital acomoda, acreditamos que o YouTube, como espaço heterotópico, através de seus vídeos memorizados, se apresenta como um campo importante de práticas culturais, dispositivo exemplar da lógica de uma comunicação em rede, pós-massiva, onde, para além do conteúdo inédito e original postado, chama atenção o acúmulo de material midiático, de todos os tempos, que encontra pouso na tela do site, o que inspira um olhar e uma usabilidade arquivista. Sob essa suspeita, pensamos esta plataforma como uma das ambiências típicas da retromania como chancela indelével da cultura pop contemporânea e assumimos assim que, historicamente, os usos sociais e culturais do tempo está marcada pelos efeitos da ciência, da técnica e das 
necessidades contemporâneas de interação e comunicabilidade, considerando, portanto, que a ascensão de determinadas redes sócio técnicas, como o YouTube, se apresentam como diapasões possíveis para entender o ambiente midiático contemporâneo, ao jogar luz à temas caroscomo a nostalgia- nos processos típicos desta nova configuração de tempo e espaço.

\section{Considerações finais}

No presente artigo propomos uma visada inicial sobre como o YouTube, interpretado como um espaço heterotópico, expõe e proporciona uma investigação sobre a centralidade do arquivo na cultura pop deste século, emergindo como um dispositivo extensor das fontes de memória do sujeito contemporâneo, pleno em oferecer reflexões sobre simbologias míticas, acionando nostalgias que encontram na plataforma um pouso seguro: a tela do site como um arquivo confiável, pronto para escavações afetivas, um repositório onde arqueólogos da mídia e do pop possam saciar suas necessidades de um retorno ao passado. Se as lembranças acontecem, frequentemente, por associação (Van Dijck, 2015) sua força parece inescapável em um mundo de fruição, consumo e mídia onde, cada vez mais o acesso ao passado é tomado como um valor em si, por vezes fetichizado (pensemos no consumo de discos de vinil, em alta no mercado fonográfico), sedutor (a oportunidade de assistir à shows de bandas que voltam à atividade, por exemplo) ou simplesmente "natural", por pertencer à uma dinâmica cíclica que por vezes parece reger os processos que envolvem a música pop.

Portanto, se inspirado pela noção do mal do arquivo, de Jacques Derrida, Reynolds (2011: 26) diz de uma necessidade contemporânea de acumular e armazenar conhecimento - uma febre de "bibliotecários que gastam muito tempo nas estantes, uma perturbação que afeta acadêmicos e antiquários em busca de testar os limites do cérebro humano para digerir informações", o YouTube e sua capacidade supostamente infindável de acumular e disponibilizar informações possui profilaxia "curativa" para essa febre e, de certa forma, a impulsiona, sendo o sintoma e a vacina. Sintoma porque, como afirma Huyssen (1996), o novo está cada vez mais associado ao passado e o arquivo não está mais confinado no museu como instituição, e sim está infectando diversas zonas da cultura e da vida cotidiana. Se antes os arranjos relativos à patrimonialização e arquivamento eram considerados possibilidades exclusivas e signos da alta cultura, agora tais visadas surgem 
como importantes lógicas do capitalismo tardio, e encadeiam a crescente velocidade das inovações técnicas e culturais, a mudança na sensibilidade da temporalidade e da percepção da experiência ao criarem artigos de consumo que conduzem ao passado.

E vacina porque ambientes digitais como estes satisfazem o que Reynolds aponta como a condição imperativa do consumidor de cultura pop da última década, a busca por memórias arquivadas do passado ou a estética retro, que suga estilos antigos, tangenciando o pastiche ou a paródia. Como sugere o autor, o pulso do "agora" está cada vez enfraquecido a cada ano que passa e a nostalgia é também água de navegação ${ }^{201}$ tranquila, dócil, plenamente satisfatória, profilaxia efetiva e efetivável em um presente desconfortável. Dessa forma, o YouTube talvez seja onde a febre arquivista pop encontra um corpo ideal para arder; possível espaço onde o pathos nostálgico se apresenta, como nota Huyssen, também como uma contestação do hiperespaço informacional e uma expressão da necessidade humana de viver em estruturas de maior duração, uma "formação reativa de corpos que querem manter sua temporalidade contra um mundo de mídia que esparge sementes de uma claustrofobia sem tempo e engendra fantasmas e simulações" (Huyssen, 1996: 123). Assim, mídias como o YouTube exercem um papel fundamental nesse contexto, onde a obsessão pela lembrança parece indicar a busca por uma âncora temporal em uma época em que os processos técnicos estão modificando rapidamente o tecido social.

Se vivemos tempos de um boom da memória, ou dos discursos a respeito dela, onde o novo está cada vez mais associado ao passado, como afirma este autor, nos motiva a pensar no crescente apego ao passado e na necessidade do sujeito atual de encontrar formas de arquivar o máximo de informações possíveis. O YouTube se situa, portanto, como a plataforma possível para a expressão de uma sensibilidade pop, sublinhada em seu aspecto retrovisor, se materializando na sociedade, nos campos da experiência e do sensível, o que nos inspira a possibilidade de sinalizá-lo como um possível regime de sentido, através de imagens, textos e sonoridades midiáticas compassivas às noções de arquivo, memória e nostalgia.

\footnotetext{
${ }^{201}$ Se o espaço heterotopico por excelência como afirma Foucault (2001) é o barco, parece plausível pensar que o YouTube cumpre o papel deste veículo em nossas navegações online.
} 
Para além, podemos pensar o YouTube como um espaço convocatório na construção de mapas de gosto e afeto, a partir de ferramentas propostas pelo site (que permitem a submissão de comentários, inscrições, compartilhamentos e outras formas de comunicação entre os usuários) que, portanto, assume aqui o papel de articulador destes sensíveis nostálgicos que se materializam entre redes digitais sócio-técnicas. Nesse escopo, grifamos a memória autobiográfica compartilhada em conversações em redes sócio técnicas (um conceito em elaboração para a continuidade da pesquisa de doutorado) como uma forma expressiva importante do pathos nostálgico e um cimento social notável para a fruição da cultura pop, onde, em linhas gerais, trata-se de considerar como a música pop atua como uma ignição de sociabilidades, reforçando a importância de denota-la como parte da nossa memória cultural coletiva. Ao atuar como um espaço heterotópico afirmativo às algumas lógicas da cultura pop, a partir de seus aspectos de sociabilidade e de interação, as apropriações do YouTube pelos usuários deixam rastros de possibilidades específicas de sentido a partir de experiências singulares, ao sinalizarem condições e percepções diferentes sobre as artes e a realidade dos modos de viver contemporâneos especificamente no referente às noções de arquivo, nostalgia e memória.

\section{Referências Bibliográficas}

Alberto, T. P. (2013). Da vida mediada pelo pop: representação e reconhecimento da cultura midiática em ficções de Nick Hornby. Dissertação. (Mestrado em Comunicação Social). Belo Horizonte: PUC-MG.

Boym, S. (2001). The future of nostalgia. Nova Iorque: Basic.

Braga, J. L. (2007). Midiatização como processo interacional de referência. In: Médola, A. S., Araujo, D. C. \& Bruno, F. (Orgs.). Imagem, visibilidade e cultura midiática: livro da XV Compós. Porto Alegre: Sulina.

Burgess, J. \& Green, J. (2009). YouTube e a revolução Digital: como o maior fenômeno da cultura participativa transformou a mídia e a sociedade. São Paulo: Aleph.

Davis, F. (1979). Yearning for yesterday: a sociology of nostalgia. Londres: Free Press.

DeNora, T. (2000). Music in everyday life. Cambridge University Press.

Foucault, M. (2001). Ditos e escritos. Estética: literatura e pintura, música e cinema. Rio de Janeiro: Forense Universitária.

Guerra, P. (2018). Raw Power: Punk, DIY and underground cultures as spaces of resistance in contemporary Portugal. Cultural Sociology, 12(2), pp. 241-259. 
Halbwachs, M. (2006). A memória coletiva. Rio de Janeiro: Centauro.

Huyssen, A. (1996). Memórias do modernismo Rio de Janeiro: Editora da UFRJ.

Reynolds, S. (2011). Retromania: pop culture's addiction to it's own past New York: Faber and Faber.

Sá, S. P. de (2014). Contribuições da teoria ator-rede para a ecologia midiática da música. Contemporânea, v12, n3.

Silveira, F. (2013). Rupturas instáveis: entrar e sair da música pop. Porto Alegre: Libretos.

Soja, E. (1995). Heterotopologies: a remembrance of other spaces in the citadel LA.In: Watson, S., \& Gibson, K. (Eds.). Postmodern cities et spaces. Oxford, UK: Blackwell.

Silverstone, R. (1999). Por que estudar a mídia? São Paulo: Loyola.

Türcke, C. (2010). Sociedade excitada: filosofia da sensação Campinas: Editora da Unicamp.

Van Dijck, J. (2007). Mediated memories in the digital age. Stanford: Stanford University Press.

Williams, R. (1992). Cultura. Rio de Janeiro: Paz e Terra. 